\title{
A Prospective Study and Clinical Trial Comparing Modified Limberg Transposition Flap Reconstruction with Excision and Primary Closure in the Treatment of Uncomplicated Sacrococcygeal Pilonidal Sinus
}

\author{
Authors \\ Atul Kumar Vyas ${ }^{1}$, Sanjay Patidar ${ }^{2}$, Kaushlendra Singh Narwariya ${ }^{3}$, \\ Krishna Pratap Singh ${ }^{4}$, Abhinav Rathi ${ }^{5}$, Rahul Jain ${ }^{6}$ \\ ${ }^{1,2}$ Associate Professor, ${ }^{3,4,5,6}$ Postgraduate Resident \\ Department of Surgery, Index Medical College Hospital and Research Centre, Indore \\ *Corresponding Author
}

Atul Kumar Vyas

Email:dratulvyas@yahoo.com, Phone: +91 7314013600

\begin{abstract}
Aim: The aim of this study was to compare surgical procedures for treatment of uncomplicated pilonidal disease between modified Limberg flap procedure with excision and primary closure.

Study Design: Prospective study.

Place and Duration: This study was conducted in Surgery Department at the Index Medical College Hospital and Research Centre during the period from August 2013 to November 2016.

Methods: This study was conducted on 62 patients with uncomplicated sacrococcygeal pilonidal disease that were alternatively allocated into two groups: group I underwent modified Limberg flap procedure; group II underwent excision and primary closure. The duration of operation, postoperative pain, duration of hospital stay, duration of incapacity for work, postoperative complications and postoperative recurrence were recorded.

Results: Duration of operation was longer in group I than in group II. However, postoperative pain was less, time to resumption of work shorter and postoperative complications were significantly fewer in group I, duration of hospital stay were same for both group I and II, during follow up period of 12 months for both group I and II.

Conclusion: Wide excision with a modified Limberg transposition flap reconstruction is a very effective procedure to operate uncomplicated pilonidal sinus, associated with a low complication rate, short hospitalization and disability and a low recurrence rate.
\end{abstract}

\section{Introduction}

The term 'pilonodal sinus' describes as a simple condition that refers to a tract or cavity which contains loose hair and commonly associated with repeated infection and small cyst or abscess formation. It is relatively a common condition affecting men twice as often as women. The estimated incidence of pilonidal sinus is 26 per 100,000 people. It is generally seen in the sacrococcygeal region, but also been described in the axilla, suprapubic area, periumblical zone and in between the fingers of barbers hand. 
Incidences of pilonodal sinus are higher in males than in female and incidences increase with obesity and hairy skin. It is generally common in people aged 15-30 years after puberty due to the effect of sex hormones on pilosebaceous glands and change in hairy growth over healthy body.

Although different surgical procedures have been used to manage sacrococcygeal pilonidal sinus, none of these proceures eliminate the postoperative morbidity including delayed wound healing, discomfort and high rate of recurrence which range between $1 \%$ and $43 \%$ in different studies.

The surgical wound can be left open to heal by open healing (secondary intention). This technique reduced wound tension facilitates trouble free healing without recurrence if all sinus are fully excised. Alternatively, by primary closure (primary intention) the wound may be closed to heal. Procedure can be categorized as midline closure techniques (with the wound lying within the natal cleft) or other techniques (where the wounds placed out with the midline). Faster tissue healing can be seen in primary closure.

In excision and primary closure, excision of the entire sinus with closure of the wound to be done. This procedure has a benefit of no wound packing. In this procedure problem is that incision tends to be situated in a deep midline cleft where there is tension and also have the propensity to accumulate hair.

To cover a sacral defect after wide excision skin flaps have been described; this keeps the scar off the midline and flattens the natal cleft. Following are the techniques available include the cleft closure, advancement flap (Karydakis procedure), local advancement flap (V-Y advancement flap), and rotational flap (Limberg flap, modified Limberg flap, gluteus maximus myocutaneous flap).

However, in the treatment of uncomplicated pilonidal disease there have been few clinical studies to compare the rhomboid fasciocutaneous transposition flap procedure (modified Limberg flap) with other conventional procedures. Limberg flap group has lower recurrence rate as compare to other flap techniques. In modified Limberg flap technique provides a more efficient flattening of the natal cleft, including the most inferior part that is inclined to invert towards the anal region, lateralization of the inferior apex of the classic Limberg flap decrease recurrences which could occur in the inferior midline. The aim of this study was to perform a clinical trial to compare the modified Limberg flap procedure with primary closure in the treatment of uncomplicated pilonidal disease.

\section{Methods}

This study was conducted in Surgery Department at the Index Medical College Hospital and Research Centre during the period from August 2013 to November 2016. Sixty-two patients who were treated for uncomplicated pilonidal disease were eligible for the study. The patients who presented with acute pilonidal abscesses, recurrent or complex pilonidal sinuses were excluded from this study.

Informed consent was taken from all patients whoever included in the study which was approved by the local ethics committee. All patients were subjected to history taking, clinical examination and laboratory investigations. The patients were alternatively allocated into two groups: group I underwent modified Limberg flap procedure; group II underwent excision and primary closure.

During operated period general anaesthesia were used for all patients. Patients were placed in prone Jack-knife position and two adhesive straps were put in each gluteal region which is helpful for better visualization of the natal cleft by pulling the adhesive strap laterally, then shaving off the hairs around the sinus and cleaning of the area done with povidone iodine. Prophylactic dose of antibiotic $1.2 \mathrm{gm}$ amoxicillin-clavulanic acid was given intravenously at the time of induction and I.V antibiotic continued for $48 \mathrm{hrs}$. Then I.V antibiotic changed to oral form for next five days. 


\section{Group I (modified Limberg flap procedure)}

In modified Limberg flap procedure rhomboid shaped incision of each side equal in length with lateralization of the inferior apex was given to excised the lesion. The rhomboid excision depth was extended to the gluteal fascia. Without giving tension the rhomboid flap was then rotated from the gluteal fascia to the excised area. By using interrupted 3/0 vicryl, subcutaneous tissue sutured and the skin was sutured separately with interrupted nylon 2/0 sutures, which was removed on the $8^{\text {th }}$ to $10^{\text {th }}$ post-operative day of procedure. A suction drain of $14 \mathrm{~F}$ was inserted at the end of the procedure, which was removed on the $3^{\text {rd }}-5^{\text {th }}$ post-operative day of procedure.

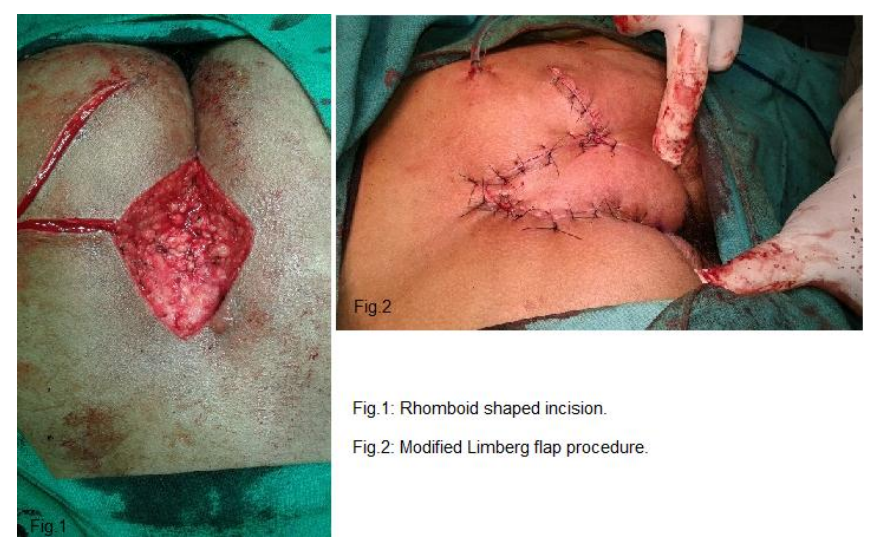

\section{Group II (excision and primary closure)}

In this procedure excised the wound, with the sinuses removed en bloc with a vertical elliptical specimen of overlying skin to the level of the sacrococcygeal fascia. Wound was approximated with $3 / 0$ vicryl interrupted subcutaneous sutures and the skin edges were closed with $2 / 0$ nylon deep interrupted mattress sutures, which was removed on the $14^{\text {th }}$ to $16^{\text {th }}$ post-operative day of procedure. Before closure, a suction drain of $12 \mathrm{~F}$ was inserted lateral to wound, which was removed on the $3^{\text {rd }}-4^{\text {th }}$ post-operative day of procedure.

Methylene blue was used to identify the tracks in either group. A single dose of prophylactic antibiotic was used immediately before incision.

In both study criteria for drain removal was 0-15 $\mathrm{ml}$ in drain per day. Patients were discharge after removal of drain. All patients were advised to come for dressing on alternate days and stitches were removed between respective (group I $8^{\text {th }}$ to $10^{\text {th }}$ and group II $14^{\text {th }}$ to $16^{\text {th }}$ ) postoperative day. All patients were advised to visit the outpatient clinic weekly for one month and then monthly for 6 months and quarterly for next 6 months postoperatively. All patients were advised to walk freely but not to exercise until stitches removed and to shave around operative site monthly, after removal of stitches.

The duration of operation, postoperative pain, duration of hospital stay, duration of absenteeism, postoperative complications and postoperative recurrence were recorded. Duration of operation was defined as the length of time between the first incision to closure. On first postoperative day, postoperative pain was assessed by visual analogue scale (VAS) from 0 (no pain) to 10 (worst pain imaginable). Duration of absenteeism was defined as the time from the date of surgery to the date on which the patient return to normal activities including employment and leisure activities. Not only peri-incisional hyperaemia, leakage of purulent secretion through the surgical wound was considered as infection.

\section{Results}

This study was conducted on 62 patients with uncomplicated sacrococcygeal pilonidal disease that were alternatively allocated into two groups, group I (31 patients) the mean age was $26 \pm 8.4$ years that underwent modified Limberg flap procedure and group II (31 patients) the mean age was $27 \pm 9.2$ years who underwent excision and primary closure procedure. No significant difference between both group regarding age, sex, preoperative symptoms and period of follow-up were there. Intermitted discharge and pain were most common symptoms.

Operative data showed that the operative time (minute) for group I was $55 \pm 7$ which was significantly more than that for group II $35 \pm 6$. Hospital stay remains the same for both the group. However, pain score, period off work and healing period significantly higher in group II than group I (Table 2). 
Table 1 : Demographic characteristics, and pretreatment symptoms of patients with uncomplicated sacrococcygeal pilonidal disease.

\begin{tabular}{|l|c|c|}
\hline & Group I $(n=31)$ & Group II $(n=31)$ \\
\hline Males:Females & $28: 3$ & $29: 2$ \\
\hline Age (years) & $26 \pm 8.4$ & $27 \pm 9.2$ \\
\hline Follow-up (months) & 12 & 12 \\
\hline & & \\
\hline Symptoms & & \\
\hline Discharge & $27(87.09 \%)$ & $28(90.32 \%)$ \\
\hline Pain & $19(61.29 \%)$ & $20(64 \%)$ \\
\hline Pruritus & $9(29.03 \%)$ & $8(25.80 \%)$ \\
\hline Bleeding & $3(9.67 \%)$ & $2(6.45 \%)$ \\
\hline
\end{tabular}

Table 2 : Outcome after surgical treatment.

\begin{tabular}{|l|c|c|}
\hline & $\begin{array}{c}\text { Group I } \\
(n=31)\end{array}$ & $\begin{array}{c}\text { Group II } \\
(n=31)\end{array}$ \\
\hline Operation time (minute) & $55 \pm 7$ & $35 \pm 6$ \\
\hline Hospitalization (days) & $4.1 \pm 1.1$ & $4.1 \pm 1.1$ \\
\hline Period off work (days) & $14 \pm 2.1$ & $21.6 \pm 3.5$ \\
\hline Pain VAS score & $2.2 \pm 1.2$ & $5.3 \pm 1.4$ \\
\hline Healing Period (days) & $14 \pm 3.1$ & $19.2 \pm 3.6$ \\
\hline
\end{tabular}

Postoperative follow-up showed that incidence of complications was significantly higher among patients of group I, which is generally seen in the inferior aspect of reconstruction and they were being treated by simple exploration under local anesthesia and dressing.

Table 3 : Postoperative complications.

\begin{tabular}{|l|c|c|}
\hline & $\begin{array}{c}\text { Group I } \\
(n=31)\end{array}$ & $\begin{array}{c}\text { Group II } \\
(n=31)\end{array}$ \\
\hline Wound infection, $n(\%)$ & $1(3.22 \%)$ & $2(6.45 \%)$ \\
\hline Seroma, $n(\%)$ & $2(6.45 \%)$ & $0(0 \%)$ \\
\hline Wound dehiscence, $n(\%)$ & $0(0 \%)$ & $5(16.12 \%)$ \\
\hline Recurrence, $n(\%)$ & $1(3.22 \%)$ & $6(19.35 \%)$ \\
\hline
\end{tabular}

\section{Discussion}

There is various surgical techniques for the eradication of the pilonidal sinuses are evidences of the lack of a completely satisfactory method of management of this surgical problem. Most of the surgical techniques which are based on seemingly sound surgical principles have some merits, but regardless of the technique employed, there is recurrence in significant proportion of cases.

Complete excision of the sinus is performed widely, but the controversy remains about what to do with the wound after excision. Surgical procedure like excision and packing, excision and primary closure, marsupialization and flap techniques have been developed for the treatment of pilonidal sinus. Despite the controversy about the best surgical procedure to treat pilonidal sinus, an ideal operation should be minimize financial cost, allow patients to return earlier to work, be simple to perform, not require a prolonged hospital stay, inflict minimal pain and have a low disease recurrence rate.

Wide excision and healing by secondary intention procedure are considerably more popular, the main advantage of this method is that all inflamed tissues are removed and the chance of recurrence is low, but hospitalization period is longer and need daily dressing, moreover time to healing is long and may exceed one year in the most unfortunate patient. As compared to open packing and marsupialization, excision and primary closure are known to provide faster healing with short hospitalization and quicker return to work. Within 3-4weeks most of the patients return to work, recurrence ratesof $7-42 \%$ have been reported following excision and primary closure, while a number of studies have reported a recurrence rate of $0-3 \%$ after rhomboid excision and Limberg flap repair outweigh the disadvantages related to an unfavourable cosmetic appearance following rhomboid excision and Limberg flap closure.

Hospital stay and time off work naturally reflect the higher morbidity of surgical techniques. In our study, patients treated with modified Limberg flap and primary closure group the mean hospital stay was $4.1 \pm 1.1$, which is exactly same in both group I and group II.

Major concern in the surgical treatment of pilonidal sinus is preventing recurrence. Postoperative complications and the recurrences, like the original sinus, develop in midline and natal cleft become deeper, an anaerobic medium is formed, resulting in increased anaerobic bacterial content. There is vacuum effect created between the large heavy buttocks sucks the anaerobic bacteria, hair and derbis into the subcutaneous fat 
tissue. After the lateralization or flattening of the midline, recurrence is less likely to occur after primary closure. In our study recurrence observed in only 1patient (3.22\%) with modified Limberg flap procedure which was significantly lower than recurrence with excision and primary closure which was observed in 6 patients i.e. 19.35\%.

The advantages of modified Limberg transposition flap reconstruction are:

- Easy to learn, perform and design.

- Reduces time to resume normal activities.

- Useful in recurrent cases of pilonidal disease.

- Scar and midline dead space is avoided.

- Useful in complex pilonidal sinuses with multiple pits where radical excision leaves large defect.

- In modified Limberg flap reconstruction, flattens the natal cleft with a large well vascularised pedicle that can be sutured without tension.

\section{Conclusion}

In conclusion, the result of this study provided further evidence that in uncomplicated pilonidal sinus, despite of longer operative time and demanding surgical skills, wide excision with a modified Limberg transpositional flap reconstruction is a very effective operative procedure which is associated with a low complication rate and disability, and with a low recurrence rate.

\section{References}

1. Karydakis GE. Easy and successful treatment of pilonidal sinus sfter explanation of its causative process. Aust N Z J Surg 1992;62:385-9.

2. Aslam MN, Shoaib S, Choudhry AM. Use of Limberg flap for pilonidal sinus- a viable option. J Ayub Med Coll Abbottabad. 2009 Oct-Dec;21(4):31-3.

3. Sondenna K, Nesvik I, Andersen E. Soreide JA: recurrent pilonidal sinus after excision with closed or open treatment: final result of a randomized trial. Eur $J$ Surg 1996;162(3):237-40.

4. Azab AS, Kamal MS, El Bassyoni F. The rationale of using the rhomboid fasciocutaneous transposition flap for the radical cure of pilonidal sinus. J Dermatol Surg Oncol 1986;12:1295-9.

5. Spivak H, Brooks VL, Nussbaum M. Friedman I: treatment of chronic pilonidal disease. Dis Colon Rectum 1996;39 (10):1136-9.

6. Mentes BB, Leventoglu S, Chihan A, Tatlicioglu E, Akin M, Oguz M. Modified Limberg transposition flap for sacrococcygeal pilonidal sinus. Surg Today 2004:34:419-23.

7. Altinktoprak F, Dikicier E, Arslan Y, Ozkececi T, Akbulut G, Dilek ON. Comparision of the Limberg flap with the $\mathrm{V}-\mathrm{Y}$ flap technique in the treatment of pilonidal disease. J Korean Surg Soc. 2013 Aug;85(2):63-7. doi: 10.4174/jkss.2013.85.2.63.Epub2013 Jul 25.

8. Lee HC, HoYH,Seow CF, Eu K W, Nyam D. Pilonidal disease in Singapore: clinical features and management. Aust N Z J Surg 2000;70:196-8.

9. Gilani SN,Furlong H,Reichardt K,Nasr AO,Theophilau G, Walsch TNExcision and primary closure of pilonidal sinus disease ; worthwhile option with an acceptable recurrence rate IrJ Med Sci 2011;108(1);173-6

10. Mentes O, Bagci M, Bilgin T, Ozgul O, Ozdemir M. Limberg flap procedure for pilonidal sinus disease: results of 353 patients. Langenbecks Arch Surg. 2008 Mar;393(2):185-9. Epub 2007 Sep 22.

11. Topgal K, Ozdemir E, Kilic K, Gokbayir $\mathrm{H}$, Ferhkose Z. Long term results of Limberg flap procedure fot treatment of pilonidal sinus : a eport of 200 cases. Dis colon Rectum 2003;46:1545-8

12. Tocchi A , Mazzoni G, Bononi M, Fornasari V, Miccini M, Drumo A, et al 
Outcome of of chronic pilonidal disease treatment after ambulatory plain midline excision and primary suture AM J Surg 2008;196:28-33

13. Ryilmaz R, Sahin M, Alimoglu O, Dasiran F. Surgical treatment of sacrococcygeal pilonidal sinus with the Limberg transposition flap. Surgery 2003;134:745-9.

14. Armstrong J, Barcia P, Pilonidal sinus disease. Arch Surg 1994;129:914-8.

15. Akinci OF, Coskun A, Uzunkoy A. Simple and effective surgical treatment of pilonidal sinus. Dis Colon Rectum 2000;43:701-2.

16. McCallum IJ, King PM, Bruce J, Healing by primary closure versus open healing after surgery for pilonidal sinus:systematic review and meta analysis.BMJ 2008;336:868-71

17. Khaira HS, brown JH. Excision and primary closure of pilonidal sinus. Ann R Coll Surg Engl 1995;77:242-4

18. Dass TA, Zaz M, Rather A, Bari S. Elliptical excision with midline primary closure versus rhomboid excision with limberg flap reconstruction in sacrococcygeal pilonidal disease: a prospective, randomized study. Indian J Surg. 2012 Aug;74(4):305-8. doi: 10.1007/s12262011-0400-9. Epub 2012 jan 7.

19. Sondenaa K, Nesvik I,Andersen E,Natas O,Soreide JK bacteriology and complications of chronic pilonidal sinus treated with excision and primary suture. Int J Colorectal Dis 1995;10:161-6

20. Iesalnieks I, Furst A, Rentsch M,Jauch KW.Primary midline closure after excision of a pilonidal sinus is associated with a high recurrence rate.Chirurg 2003;74:4618.

21. Azab AS, Kamal MS, el Bassyoni F.The rationale of using the rhomboid fasciocutaneous transposition flap for the radical cure of pilonidal sinus.J Dermatol Surg Oncol 1986;12:1295-9.
22. Muzi MG, Milito G, Cadeddu F, Nigro C, Andreoli F, Amabile F, et al . Randomized comparison of Limberg flap versus modified primary closure for the treatment of pilonidal disease. AM J surg 2010; 200:9-14

23. Lieto E, Castellano P, Pinto M, Zamboli A, Pignatekki C, Gallezia G, Dufourmentel Rhomboid flap in the radical treatment of primary and recurrent sacrococccygeal pilonidal disease. Dis Colon Rectum 2010;53:1061-8

24. Bascom JU . Pilonidal sinus. Curr Pract Surg 1994;6;175-80

25. Abu Galala KH, Salam IM, Abu Samaan KR,et al.Treatment of pilonidal sinus by primary closure with a transposed rhomboid flap compared with deep suturing; a prospective randomized clinical trial Eur Jsurg 1999;165:468-72

26. Akca T, Colak T , Ustonsoy B, Kanik A, Aydin S. Randomised clinical trial comparing primary closure with the Limberg Flap in the treatment of primary sacrococcygeal pilonidal disease Br J Surg 2005;92:1081.

27. Mahdy T. Surgical treatmental of pilonidal disease: primary closure or flap reconstruction after reconstruction. Dis Colon rectum 2008;51(12);1816-22[Epub 2008, /October 21]

28. Marks J, Harding KG, Hughs LE, Ribeiro CD. Pilonidal sinus excision- healing by open granulation Br J Surg 1985;72:63740

29. Eryilmaz R,Sahin MAlimoglu O,Dasiran F.Surgical treatment of sacrococcygeal pilonidal sinus with the Limberg transposition flap.Surgery 2003;134:745-9.

30. Onder A, Girgin S, Kapan M, Toker M, Arikanoglu Z, Palanci Y et al. Pilonidal sinus disease: risk factors for postoperative complications and recurrence. Int Surg. 2012 Jul-Sep;97(3):224-9. doi: 10.9738/CC86.1. 
31. Bascom J. Skin flaps for pilonidal disease. Ann Plast Surg. 1998 Sep;41(3):338

32. Foss MV. Pilonidal sinus :excision and closure. Proc R Soc Med 1970;63:752-8.

33. Kapan M,Kapan S. Pekmezci S,Durgun V.Sacrococcygeal pilonidal sinus disease with Limberg flap repair. Tech Coloproctol 2002;6:27-32.

34. Rossi P,Rusoo F,Gentileschi P,et al.The pilonidal sinus: its surgical management, our experience and a review of the literature.G Chir 1993;14:120-3.

35. Jamal A, Shamim M, Hashmi F, Qureshi MI. Open exicision with secondary healing versus rhomboid excision with Limberg transposition flap in the management of sacrococcygeal pilonidal disease. J Pak Med Assoc. 2009 Mar;59(3):157-60.

36. Raghubir S,Pavithran $M$ adipo-fasciocutaneous flaps in the treatment of pilonidal sinus:experience with 50 cases. Asian J surg 2005;28:198-201. 